\title{
Disentangling the
}

\section{relationships between job}

\section{burnout and perceived health in a military sample}

\author{
Amiram D. Vinokur, ${ }^{1, *, \dagger}$ Penny F. Pierce ${ }^{2}$ and Lisa Lewandowski-Romps ${ }^{1}$ \\ ${ }^{1}$ Institute for Social Research, University of Michigan, Ann Arbor, Michigan, USA \\ ${ }^{2}$ School of Nursing, Institute for Social Research, University of Michigan, Ann Arbor, \\ Michigan, USA
}

\begin{abstract}
Summary
The reciprocal and longitudinal effects of job burnout and perceived health were examined in a sample of Air Force personnel $(\mathrm{N}=1,009)$ deployed to the wars in Iraq, Afghanistan and supporting locations. We estimated a structural equation model that described the relationships between the job burnout and perceived health and their effects on each other over time. The data fit the model exceedingly well as demonstrated by the goodness of fit measures (normed fit index, non-normed fit index, comparative fit index $=0.97,0.99,0.99$, respectively, and root mean square error of approximation =0.01). As hypothesized, burnout and perceived health are negatively associated with each other $(\mathrm{r}=-0.33)$. Over a one-year follow-up period, perceived health predicted a decrease in job burnout $(\beta=-0.20)$ and job burnout predicted a decrease in perceived bealth $(\beta=-0.10)$. The predicted effect of perceived health on job burnout was shown to be significantly larger than the effect of burnout on health. This latter finding is interpreted to result from the conceptualization and measurement of job burnout as limited to a single life domain and also to the possibility that job burnout fluctuates with changing working conditions over time more than perceived health. Copyright (C) 2009 John Wiley \& Sons, Ltd.
\end{abstract}

\section{Key Words}

job burnout; perceived health; military deployment

\section{Introduction}

The vast research on job burnout has already demonstrated the importance of this phenomenon to the study of organizations as it is associated

\footnotetext{
* Correspondence to: Amiram Vinokur, Institute for Social Research, 426 Thompson Street, Ann Arbor, MI 48106-1248, USA.

†E-mail: avinokur@umich.edu
}

with job performance and organizational citizenship behaviour (Taris, 2006) and also, although weakly, associated with other organizational behaviours such as absenteeism and job turnover (Schaufeli, 2003). Job burnout is therefore a likely contributor to organizational effectiveness. Thus, burnout has received a great deal of attention in the literature on organizational behaviour. In addition, there is a growing literature that links job burnout to poor health through various negative health behaviours such as sleep disturbance and through other physiological and biological 
mechanisms (Melamed, Shirom, Toker, Berliner, \& Shapira, 2006). In this literature, the investigated link is usually focused on a relationship between a specific type of health problem and burnout. For example, various studies documented associations between burnout and depression (Schaufeli \& Enzmann, 1998), certified sickness absences (Ahola et al., 2008), and insomnia (Armon, Shirom, Shapira, \& Melamed, 2008). A study by Gorter, Eijkman and Hoogstraten (2000) also linked job burnout to health complaints, which, taken together, can be thought of as an indication of general health. However, while there are demonstrated links between specific health problems or complaints and job burnout, the question remains regarding the link between burnout and general health. We shall return to this question following an elaboration of the conceptual frame of job burnout as defined in this paper.

\section{Job burnout}

The original formulations of burnout and its measurement as represented, for example, in the work of Maslach and colleagues, focused on emotional exhaustion, depersonalization and reduced personal accomplishment (Maslach, 1982; Maslach \& Jackson, 1981). More recent developments by Shirom and colleagues (Hobfoll \& Shirom, 2000; Shirom, 1989) conceptualized job burnout within the context of the conservation of resources (COR) theory as a result of depletion of energetic resources that produce physical fatigue, emotional exhaustion and cognitive weariness (for more comprehensive reviews of the conceptualization and measurement issues of burnout, see Halbesleben \& Buckley, 2004; Schaufeli \& Buunk, 2003; Shirom, 2009).

\section{Physical and perceived health}

From a biological point of view, physical health is a multidimensional construct. Various types of diseases are weakly correlated and ill health can be a function of different number or types of diseases or disabilities. General physical health is often assessed using composite measures (i.e. indices) that are based on records or self-reports of physical and mental illnesses or conditions, physical limitations and disabilities, and sometimes also medication use. Unlike the assessment of physical health, perceived health is often assessed more directly with the individuals reporting their subjective assessment of their global health, health problems and functioning. While physical health is multidimensional, it is quite possible that perceived health is a unidimensional psychological construct and, consequently, the answers individuals give to relevant questions regarding how they perceive their health should form a unidimensional scale.

It has been shown that assessments of physical health are correlated with ratings provided in response to a global question regarding perceived general health such as 'In general, would you say your health is poor, fair, good, very good or excellent?' (Benyamini, Leventhal, \& Leventhal, 1999). In some studies, this question is supplemented by two or three additional questions about having health problems and functional limitations as a result of health problems (Stewart \& Ware, 1992). This more global and subjective self-rated assessments of general health is often referred to as self-rated health or perceived health. Although global and subjective, perceived health was demonstrated to predict mortality in 27 studies even when a number of health status indicators and other relevant covariates were controlled (Idler \& Benyamini, 1997).

\section{Burnout and perceived health}

Given the literature that links job burnout and specific health problems and the studies highlighting the importance of perceived health as a construct of general health, we hypothesize that job burnout and general health are related to each other. However, the main purpose of this paper is to disentangle their longitudinal relationship. That is, we seek to examine their possible influence on each other over time. There is reason to believe that job burnout, which represents the depletion of physical, emotional and cognitive resources in the central domain of work (Hobfoll \& Freedy, 1993; Hobfoll \& Shirom, 2000; Westman, Hobfoll, Chen, Davidson, \& Laski, 2005), can lead over time to a deterioration of health. Similarly, health represents a global resource needed for normal functioning in nearly all life domains. Poor health is therefore indicative of chronic stress (Halford, Anderzén, \& Arnetz, 2003) or depletion of specific resources needed to combat job burnout and therefore is hypothesized to increase job burnout over time. 
In turn, good health makes one more resilient to the development of job burnout.

Compared with burnout, global health is determined by a wider range of biological physiological and physical functioning factors than job burnout. While the assessment of perceived health by the individual is likely to include all or any of these factors, the assessment of job burnout is primarily an assessment of a more limited psychological experience. It does not include such experiences as pain, physical discomfort and limitations in physical functioning. Perceived change in ones health is likely to reflect the realization of a fairly large and relatively permanent change in ones' internal state or physical functioning that is likely to have a marked effect on the ability to perform ones' occupational role. As a more robust construct, it is therefore expected to have a strong effect on job burnout. In contrast, job burnout, being affected by more restricted set of factors than global health, could sometimes be caused by relatively temporary occupational and environmental factors. This may be, for example, the case of soldiers serving in the armed forces whose work conditions may change with the type and tempo of deployments, the duties to which they are assigned, and unexpected changes of their commander, supervisors and teammates. Thus, the individual's job environment and its effect on burnout are more likely to change than his or her global health. So, compared with the relative stability of global health, job burnout at one time may be a poorer predictor to the next. For all these reasons, global health is hypothesized to have a stronger effect on burnout over time than the effect of job burnout on health.

In summary, we hypothesize that job burnout and perceived health are related to each other (Hypothesis 1). We also hypothesize that, over time, job burnout predicts a decrease in perceived health (Hypothesis 2), and perceived health predicts a decrease in job burnout (Hypothesis 3). Finally, we hypothesize that the predicted effect of perceived health on job burnout is stronger than the predicted effect of job burnout on perceived health (Hypothesis 4).

The above set of hypotheses is tested using a large stratified sample of Air Force personnel who were deployed during the period of the wars in Afghanistan and Iraq. Military deployments during time of war introduce peak times of intense activities and therefore the potential to increase both job burnout and poor health. Mobilization of active duty, reserve and National Guard members called upon thousands to leave their families, civilian jobs and the security of everyday life to meet the challenges of a variety of threatening and uncertain missions. Never have the operational demands of a downsized all-volunteer force been so high, placing an extraordinary requirement to serve for extended periods of time or respond to multiple deployments in a relatively short period. The demands of the war environment places extraordinary demands on the individual who performs his or her duties for extended periods with little rest or recovery time but whose job demands discipline, steady reactions to uncertain events, and an unusually high state of vigilance and concentration. The accumulation of multiple strains resulting from singular stressful events appears to predict a decrease in physical, psychological and social well-being (Kanner, Coyne, Schaefer, \& Lazarus, 1981). It is less clear how prolonged and sustained exposure to these events influences job burnout and poor health among deployed military members and how they relate to each other over time.

In sum, deployments in the armed forces are akin to changing a good part of the working environment with the potential of changing levels of burnout over relatively short time periods. This context provides a unique opportunity to examine potential differential effects between job burnout and perceived health over time.

\section{Method}

This study was conducted with the approval of The University of Michigan's Health Sciences Institutional Review Board (IRB) and the IRB of the Uniformed Services University of the Health Sciences.

\section{Sampling and data collection}

The Defense Manpower Data Center (DMDC) provided a probability sample with contact information for 2,250 men and women deployed during the period of 7 October 2001 to the time of the sample request (September 2004). A random stratified sample was constructed with 52 per cent men, 31 per cent from the Active Duty component of the Air Force, 34 per cent from Reserve and 35 per cent from the National Guard. Included in the sample were nearly equal number of parents and non-parents and those serving in 


\section{A. D. Vinokur, P. F. Pierce and L. Lewandowski-Romps}

the theatre of war versus elsewhere during the same period. The theatre of war was defined as deployment to at least one of the following locations: Iraq, Afghanistan, Qatar, Kuwait or Saudi Arabia.

All men and women in the probability sample were sent a small incentive (metal pin) with a recruitment letter inviting them to participate in the study. They were then called to complete a short telephone interview (about $20 \mathrm{~min}$ ). Those participating in the interview were then sent another incentive (commemorative pen) with a mailed self-administered questionnaire (SAQ). The option of completing the SAQ online (on the web) was also offered. Of the 2,250 men and women who were invited to the study, 1,451 (64 per cent) completed the telephone interview (Of the letters sent to 2,250 men and women, 141, or 6 per cent, were returned because of inaccurate addresses and these individuals could not be located by other searches.) and 1,009 (45 per cent) provided data using the SAQ (60 per cent mail return, 40 per cent online). Approximately 1 year later, all participants received an announcement letter and another small incentive gift inviting them to complete a follow-up SAQ. Of the 1,009 men and women completing the initial SAQ, 796 (79 per cent) also completed the followup SAQ or its equivalent online (32 per cent and 68 per cent, respectively). The demographic characteristics of the sample including military background information are provided in Table I.

\section{Measures}

Basic demographic information. Basic demographic information about the respondents was collected with standard questions used in national surveys by the Institute for Social Research. The questions provided data on age, gender, education, marital status, income, ethnic/racial identification and dependent children.

Military background information. Military background information regarding rank, service component (active versus Reserve and Guard) and deployment in the theatre of war (versus elsewhere) was obtained from the respondent and from the database provided by DMDC.

Job burnout. Job burnout was assessed using 9 of the 12 items $(\alpha=0.95)$ of the ShiromMelamed Burnout Measure (SMBM). This
Table I. Demographic and military background of sample respondents $(N=1,009)$.

\begin{tabular}{|c|c|}
\hline Characteristics & Percent $(n)$ \\
\hline \multicolumn{2}{|l|}{ Age $(M=38.2$ years $)$} \\
\hline 30 and younger & $27.2(274)$ \\
\hline $31-40$ & $31.9(322)$ \\
\hline 41 and older & $40.9(413)$ \\
\hline \multicolumn{2}{|c|}{ Education ( $M d=14.9$ years) } \\
\hline 13 years and below & $23.2(234)$ \\
\hline 14 years & $23.7(239)$ \\
\hline 15 years and above & $52.4(529)$ \\
\hline \multicolumn{2}{|l|}{ Gender } \\
\hline Male & $50.1(506)$ \\
\hline Female & $49.9(503)$ \\
\hline \multicolumn{2}{|c|}{ Household income $(M d=\$ 55,365.00)$} \\
\hline 39,999 and below & $29.2(295)$ \\
\hline $40,000-59,999$ & $24.4(246)$ \\
\hline 60,000 and above & $42.3(427)$ \\
\hline \multicolumn{2}{|l|}{ Marital status } \\
\hline Married & $53.1(536)$ \\
\hline Unmarried & $46.3(467)$ \\
\hline \multicolumn{2}{|l|}{ Race } \\
\hline White & $76.5(772)$ \\
\hline Non-white & $22.0(222)$ \\
\hline \multicolumn{2}{|c|}{ Dependent child (during deployment) } \\
\hline Yes & $42.4(428)$ \\
\hline No & $52.5(530)$ \\
\hline \multicolumn{2}{|l|}{ Rank } \\
\hline Officer & $25.5(257)$ \\
\hline Enlisted & $73.4(741)$ \\
\hline \multicolumn{2}{|l|}{ Component } \\
\hline Active & $25.5(257)$ \\
\hline Reserve & $39.0(394)$ \\
\hline Guard & $35.5(358)$ \\
\hline \multicolumn{2}{|l|}{ Deployment location } \\
\hline Theatre of war* & $65.1(657)$ \\
\hline Elsewhere $^{\dagger}$ & $34.9(352)$ \\
\hline
\end{tabular}

* Theatre locations include Iraq, Kuwait, Qatar, Afghanistan and Saudi Arabia. Participants in the theatre of war may have also served in other locations.

'Participants deployed 'elsewhere' were not deployed in any location defined as 'in theatre.'

$\mathrm{M}$ : mean; Md: median.

measure has been validated in several studies (e.g. Melamed et al., 2006; Shirom \& Melamed, 2006). The SMBM includes three subscales: (1) physical fatigue; (2) emotional exhaustion; and (3) cognitive weariness. For assessing physical fatigue we used the items 'I feel tired; I feel physically fatigued; I feel exhausted.' For assessing emotional exhaustion we used the items 'I feel like my emotional "batteries" are "dead"; 'I feel emotionally burned out in my job'; 'I feel emotionally fatigued'. For assessing cognitive weariness we used the items 'I am too tired to think 
clearly'; 'I have difficulty concentrating'; 'My thinking process is slow'. Respondents completing the SMBM were asked to rate the frequency of each feeling while at work in the Air Force during the past month. All items are scored on a 7-point frequency scale, ranging from $1=$ almost never to $7=$ almost always.

Perceived Health. Perceived health was assessed with four questions $(\alpha=0.78)$ that were based on similar items from the Medical Outcome Study (Stewart \& Ware, 1992). Participants were asked to answer the following questions: 'In general, would you say your health is excellent, good, fair, or poor?'; 'To what extent do you have any particular health problems?' $(1=$ never/no extent to $5=$ a very great extent); 'Thinking about the past 2 months, how much of the time has your health kept you from doing the kind of things other people your age do?' $(1=$ none of the time to 5 = all of the time); and 'To what extent do you feel healthy enough to carry out things that you would like to do?' $(1=$ never/no extent to $5=\mathrm{a}$ very great extent). The scoring of the first three items was reversed so that in all four items a higher score represents better health.

Analysis of participation and attrition. Using the data obtained from the DMDC on each person's age, gender, parenthood status, rank (officer versus enlisted), component (Active Duty, Reserve or Guard), deployment location in terms of theatre of war (versus elsewhere) and length of deployment, an attrition analysis was conducted to determine possible bias in the characteristics of respondents who participated versus those who did not participate. A logistic regression analysis was used by including all the demographic and military background variables to predict participation at Time 1 (T1). Of the predictors of participation at T1, age, female gender, parental status, rank and component were found as significant predictors (odds ratio $=1.04,1.20,1.25$, 1.69 and 1.20 , respectively, $p<0.05$ ). Higher response rates were found for the older participants (mean age 38.2 versus 33.9), females (46 per cent versus 43 per cent males), parents (51 per cent versus 39 per cent non-parents), officers (59 per cent versus 41 per cent non-officers) and reserve and guard members (48 per cent versus 37 per cent active duty). In contrast, deployment in the theatre of war (versus elsewhere) and length of deployment were not found as predictors of participation. In conclusion, there are several demographic and military variables that bias the representation of our overall sample. However, even with this bias, the generalizability of our findings is strengthened by the resulting greater coverage of particular groups in the military, such as females and parents, who are typically underrepresented in research.

A total of 796 respondents completed the Time 2 (T2) questionnaire for a 79 per cent response rate. Thus, the same logistic analysis described above was conducted to predict attrition at T2 based on the data from T1. Of the various predictors, only age was found to significantly predict participation at T2 (odds ratio $=1.03 ; p<0.01$ ) Participants were older than non-participants $(M$ $=38.5$ versus 34.6 respectively). Furthermore, we examined attrition at T2 by comparing the T1 reports of the participants and the non-participants that included various mental health and functioning variables such as depression, role functioning as well as perceived health and job burnout. None of these comparisons yielded a statistically significant difference. It seems that attrition did not play a meaningful role in altering the representativeness of the sample used for our analyses.

\section{Results}

Our main analysis included the estimation of a structural equation model that was constructed to represent our four hypotheses. Our model also included two demographic control variables, gender and education, that proved to be related, respectively, to job burnout and perceived health. The perceived health latent factor in each time wave was indicated by the four single items that make up the measure. The job burnout latent factor was modelled as a secondary factor with its three component factors, physical fatigue, emotional exhaustion and cognitive weariness, as first-order factors. Each of the three component factors was indicated by the three single items from the respective scale. The model also included correlations between the errors of the respective indicators of the first-order factors of the job burnout and of perceived health across time, and constrains for factor loadings of the indicators of all first- and second-order factors across time. We used EQS version 6.1 to estimate the model using maximum likelihood method with the Yuan and Bentler (2000) EM-ML imputation procedure, which also included the scaled chi-square to adjust for missing data bias, and the Jamshidian 


\section{A. D. Vinokur, P. F. Pierce and L. Lewandowski-Romps}

and Bentler (1999) robust method for adjusting standard errors. Following widely accepted recommendations (e.g. Boomsma, 2000) we report three goodness-of-fit indices: the normed fit index (NFI), the non-normed fit index (NNFI, also known as TLI) and the comparative fit index (CFI). We also report the value of the misfit index known as root mean square error of approximation (RMSEA). Fit indices close or above 0.95 and RMSEA below 0.06 indicate a close fit of the data to the model (Hu \& Bentler, 1999).

Since we conceptualized global perceived health as a reflective latent factor we tested whether our indicators for this construct form a unidimensional factor. We therefore estimated a model with T1 and T2 perceived health factors with their indicators, including equality constrains for T1 and T2 loadings, correlations between respective errors across time and a correlation between the two factors. The results provided good fit, with Yuan and Bentler $\chi 2(18, n=1,009)=$ 104.48; NFI $=0.96, \mathrm{NNFI}=95, \mathrm{CFI}=0.97$; and
RMSEA $=0.06$ (CI 0.04-0.07). They clearly demonstrate that perceived health can be considered a unidimensional construct.

The estimated model for testing our hypotheses and its results is displayed in Figure 1. The means, standard deviations and correlations of all are displayed in Table II. The results shown in Figure 1 and in Table II are based on an EM-ML imputation of the data as mentioned above. Prior to the estimation of the model (Figure 1), we estimated a measurement model that included all of the first order factors and their indicators. The estimation produced a Yuan and Bentler $\chi 2$ (267, $n=1,009$ ) of 540.17 ; an NFI, NNFI and CFI of $0.98,99$ and 0.99, respectively; and an RMSEA of $0.01(\mathrm{CI}=0.00-0.01)$. We then proceeded to estimate the structural model, which is displayed with the results in Figure 1 . The estimation resulted in Yuan and Bentler $\chi 2(332, n=1,009)$ $=687.19$, with excellent goodness-of-fit measures, NFI $=0.97$, NNFI $=99$ and $\mathrm{CFI}=0.99$, and RMSEA $=0.01(\mathrm{CI}=0.01-0.02)$.
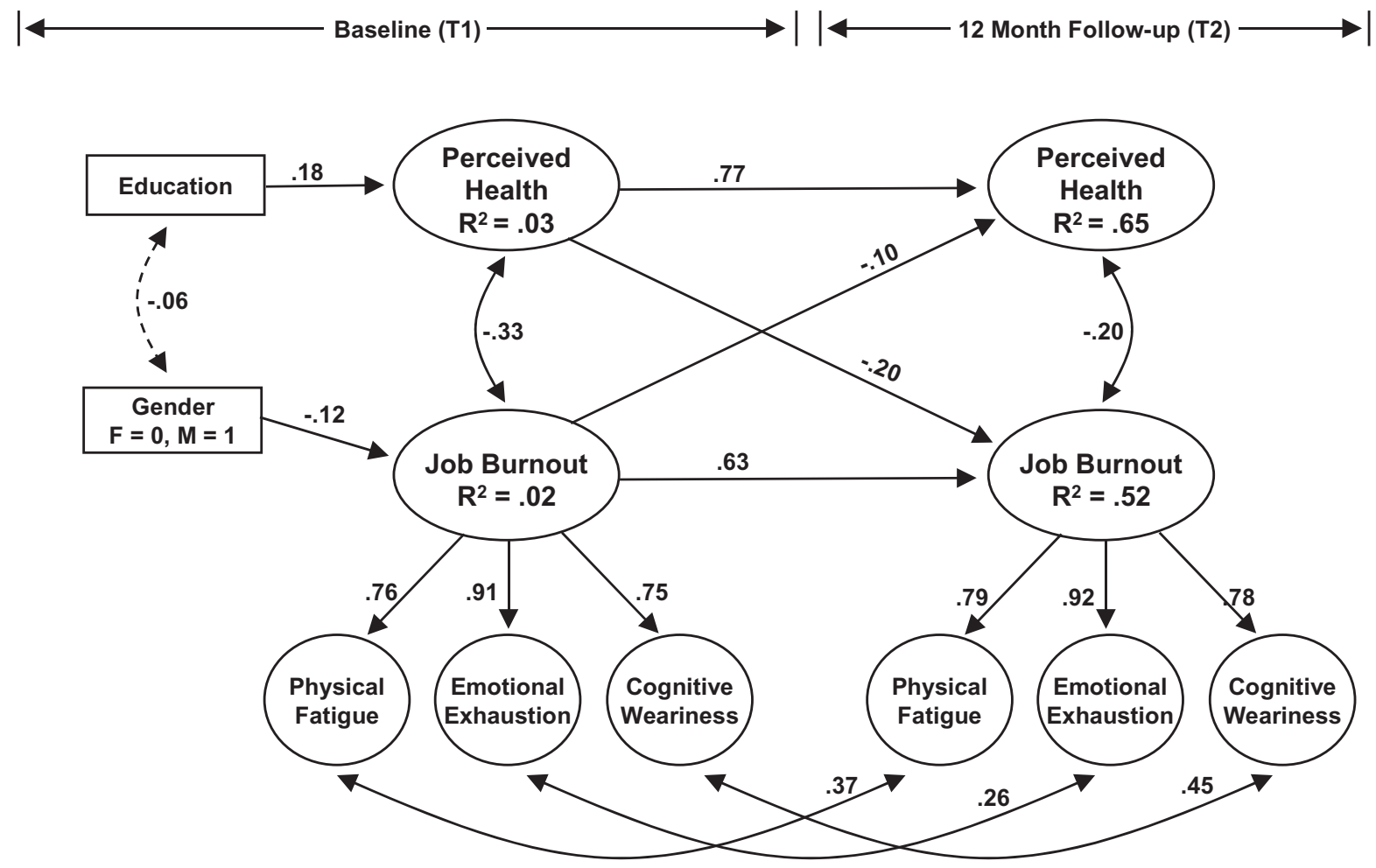

Figure 1. Longitudinal effects of perceived health and job burnout. All solid line paths or correlations are statistically significant at 0.05 . Double arrow curves between perceived health and job burnout represent correlations between the disturbances (residuals). Yuan and Bentler $\chi 2(332, n=1,009)=687.19$. NFI, NNFI, CFI $=0.97$, 0.99, 0.99, respectively, and RMSEA $=0.01$. 


\section{Job burnout and health}

Table II. Correlations, means and standard deviation (SD) for the model constructs in Figure 1.

\begin{tabular}{lrcccccccccc}
\hline Variable & 1 & 2 & 3 & 4 & 5 & 6 & 7 & 8 & 9 & 10 & 11 \\
\hline Education & - & - & - & - & - & - & - & - & - & - & - \\
Self-rated health, T1 & 0.17 & - & - & - & - & - & - & - & - & - & - \\
Self-rated health, T2 & 0.20 & 0.74 & - & - & - & - & - & - & - & - & - \\
Job burnout, T1 & -0.05 & -0.31 & -0.36 & - & - & - & - & - & - & - & - \\
Job burnout, T2 & -0.07 & -0.40 & -0.48 & 0.72 & - & - & - & - & - & - & - \\
Physical fatigue, T1 & 0.02 & -0.25 & -0.28 & 0.83 & 0.56 & - & - & - & - & - & - \\
Emotional exhaustion, T1 & -0.04 & -0.27 & -0.32 & 0.91 & 0.66 & 0.65 & - & - & - & - & - \\
Cognitive weariness, T1 & -0.08 & -0.29 & -0.34 & 0.88 & 0.65 & 0.61 & 0.73 & - & - & - & - \\
Physical fatigue, T2 & -0.03 & -0.35 & -0.41 & 0.64 & 0.87 & 0.61 & 0.55 & 0.54 & - & - & - \\
Emotional exhaustion, T2 & -0.08 & -0.33 & -0.41 & 0.66 & 0.93 & 0.48 & 0.67 & 0.55 & 0.73 & - & - \\
Cognitive weariness, T2 & -0.06 & -0.41 & -0.46 & 0.65 & 0.91 & 0.46 & 0.57 & 0.68 & 0.71 & 0.77 & - \\
Mean & 5.83 & 4.08 & 4.04 & 2.94 & 2.95 & 3.73 & 2.85 & 2.44 & 3.68 & 2.88 & 2.46 \\
SD & 1.68 & 0.67 & 0.67 & 1.22 & 1.19 & 1.40 & 1.56 & 1.27 & 1.35 & 1.47 & 1.17 \\
\hline
\end{tabular}

$n=1,009$. Correlation coefficients larger than 0.06 are statistically significant at 0.05 . A more detailed matrix with the means, $\mathrm{SD}$ and correlations among all the measured variables including the indicator parcels is available upon request from the authors.

T1: Time 1; T2: Time 2.

The more specific results of the estimated model show that perceived health and job burnout are negatively correlated at T1 $(r=-0.33, p<0.001)$ and their residuals (disturbance terms) are also negatively correlated at T2 $(r=-0.20, p<0.001)$. These significant correlations support Hypothesis 1. Further, in support of Hypothesis 2, job burnout at $\mathrm{T} 1$ predicted a decrease in perceived health at T2 $(\beta=-0.10, p<0.001)$ and, in turn, in support of Hypothesis 3, perceived health at $\mathrm{T} 1$ predicted a decrease in job burnout at T2 $(\beta=$ $-0.20, p<0.001)$. To test whether the effect of perceived health on job burnout is significantly stronger than the effect of burnout on perceived health (cf. Hypothesis 4) we estimated a model in which these effects (i.e. the coefficients of the diagonal paths) were constrained to be equal. This model produced a larger Yuan and Bentler $\chi 2(333, n=1,009)=703.77$ than the model without the constraint. The difference in $\chi^{2}$ was 16.58 , which is, for 1 degree of freedom, statistically significant at 0.001 . The significant increase in $\chi^{2}$ indicates different sizes of these effects, that is, perceived health had a stronger effect on burnout than that of burnout on perceived health, thus supporting Hypothesis 4. It is also noticeable that education increased T1 perceived health $(\beta \mathrm{s}=$ $0.18, p<0.001)$. Similarly, male gender was associated with lower burnout at T1 $(\beta=-12$, $p<0.001$ ).

As the lag between T1 and T2 is relatively long and extends to 1 year, the accuracy of the size of the longitudinal effects may be questioned. Greater fluctuation in job burnout over time compared with those in perceived health-as may be suggested by the smaller stability effects (i.e. $\beta s=$ 0.63 for job burnout versus 0.77 for perceived health)—could be the reason for its smaller impact on perceived health. To examine this issue, we tested an alternative though equivalent model using replacement rules (cf. Lee \& Hershberger, 1990) in which we removed the longitudinal paths and, instead, added reciprocal paths at T2 between perceived health and job burnout. This alternative model resulted in equally good fit to the data with a path from burnout to perceived health smaller in size than the reciprocal path from perceived health to burnout $(\beta s=-0.16$, and -0.27 , respectively, both $p<0.001)$. So, given that the same pattern of differential impact applies in both analyses, it seems clear that the effect of job burnout on perceived health is smaller than the effect of perceived health on job burnout.

As most studies on perceived health are based on the single question regarding general health ('In general, would you say your health is excellent, good, fair, or poor?'), we tested the model in Figure 1 substituting the latent factor of perceived health with another that is indicated by the one measured variable based on the single question of general health. In this model we set the variance of the error term to the variance of the variable multiplied by one minus the alpha. The alpha of this one-item measure was estimated 
as 0.60 . The estimated model resulted in a Yuan and Bentler $\chi 2(194, n=1,009)=408.47$ with excellent goodness-of-fit measures, NFI $=0.97$, $\mathrm{NNFI}=99$, and CFI $=0.99$, and $\mathrm{RMSEA}=0.02$ $(\mathrm{CI}=0.01-0.03)$. A similar pattern of results regarding the longitudinal diagonal paths of influence repeated itself with a statistically significant path from T1 perceived health to T2 burnout $(\beta=-0.12, p<0.001)$ and larger than the path from T1 burnout to T2 perceived health ( $\beta=-0.001$, not significant). It is interesting to note that the size of the path from T1 perceived health to T2 burnout is nearly half of the path based on the four-item broader measure of perceived health (cf. Figure 1) and the path from burnout to health is essentially zero. The stronger paths of longitudinal influence based on multiitem measure of perceived health indicate the importance of assessing global health in a more comprehensive way, that is, using additional health issues such as physical functioning, than is achieved with the one-item global measure.

\section{Discussion}

The underlying framework of our research was based on the COR theory that views burnout as a consequence of depletion of resources in ones' occupational domain (Hobfoll \& Freedy, 1993). Because depletion of resources in the critical life domain of work increases likelihood and severity of job burnout, it also adversely affects health through various mediating mechanisms. Moreover, as health is one of the most important resources for an individual's functioning in nearly all life domains, when this resource is depleted, it will surely affect resources in most other domains including the job in ones' occupational domain. The findings of this study supported all of our hypotheses. Firstly, they demonstrated crosssectional negative associations between perceived health and job burnout. Secondly, they demonstrated that over time, perceived health predicted a decrease in job burnout and that job burnout predicted a decrease in perceived health. Thirdly, and lastly, the findings demonstrated that the longitudinal effect of perceived health on burnout is stronger than the effect of burnout on perceived health. Even when we estimated a model in which the diagonal longitudinal effects of the constructs were replaced with reciprocal effects between perceived health and job burnout, the stronger effect of perceived health on job burnout than the reverse was clearly demonstrated again, with each construct having a significant effect on the other. This latter finding is interpreted to result from the conceptualization and measurement of job burnout as limited to a single life domain and also to the possibility that job burnout fluctuates with changing working conditions over time more than perceived health.

It is important to note at least two important limitations of this study. The first limitation arises from the absence of control for variables that may affect job burnout and perceived health. For example, in several studies, depressive symptoms and neuroticism have been shown to correlate with job burnout (e. g. Schaufeli \& Enzmann, 1998). Other studies indicate that neuroticism influences responses to items that assess perceived health (Chapman, Buberstein, Sörensen, \& Lyness, 2006; Costa \& McCrae, 1987; Goodwin \& Engstrom, 2002). Future studies on the relationship between burnout and health should therefore control for these possible confounding variables. The second limitation is related to the external validity of the findings as they are based on a unique military sample of Air Force personnel serving at times of war. Recent studies found that soldiers who served in Iraq and Afghanistan were at significant risk for mental health problems (Hoge et al., 2004). Thus, it is possible that the findings of the study based on a military sample do not represent the relationship between the key constructs in a general population.

Finally, it would be informative if future research examines the relationship between perceived health and general burnout rather than job burnout, which is specific to the domain of occupational life and work. And, similarly, future research could reveal the effect of chronic job burnout on health by extending the research design to include a question that focuses on longer than 1-month period of experiencing the burnout symptoms or, alternatively, collect burnout information in multiple close time periods lasting for a year or longer. It could be hypothesized that in both cases, the effect of burnout on perceived health would be larger than the one demonstrated in our investigation.

\section{Acknowledgment}

This research was sponsored by the TriService Nursing Research Program (N04-P02); however, the information or content and conclusions do not necessarily represent the official position or policy of, nor should any 


\section{Job burnout and health}

official endorsement be inferred by, the TriService Nursing Research Program, the Uniformed Services University of the Health Sciences, the Department of Defense, or the US Government.

\section{References}

Ahola, K., Kivimaki, M., Honkonen, T., Virtanen, M., Koskinen, S., Vahtera, J., \& Lönnqvist, J. (2008). Occupational burnout and medically certified sickness absence: A population-based study of Finnish employees. Journal of Psychosomatic Research, 64(2), 185-193.

Armon, G., Shirom, A., Shapira, I., \& Melamed, S. (2008). On the nature of burnout-insomnia relationships: A prospective study of employed adults. Journal of Psychosomatic Research, 65(1), 5-12.

Boomsma, A. (2000). Reporting analyses of covariance structures. Structural Equation Modeling, 7(3), 461-482.

Benyamini, Y., Leventhal, E.H., \& Leventhal, H. (1999). Selfassessments of health. What do people know that predicts their mortality? Research on Aging, 21, 477-500.

Chapman, B.P., Duberstein, P.R., Sörensen, S., \& Lyness, J.M. (2006). Personality and perceived health in older adults: The five factor model in primary care. The Journals of Gerontology Series B, Psychological Sciences and Social Sciences, 61, P362-P365.

Costa, P.T., \& McCrae, R.R. (1987). Neuroticism, somatic complaints and disease: Is bark worse than the bite? Journal of Personality, 55, 299-316.

Goodwin, R., \& Engstrom, G. (2002). Personality and the perception of health in the general population. Psychological Medicine, 32, 325-332.

Gorter, R.C., Eijkman, M.A.J., \& Hoogstraten, J. (2000). Burnout and health among Dutch dentists. European Journal of Oral Sciences, 108(4), 261-267.

Halbesleben, J.R.B., \& Buckley, M.R. (2004). Burnout in organizational life. Journal of Management, 30(6), 859879.

Halford, C., Anderzén, I., \& Arnetz, B. (2003). Endocrine measures of stress and self-rated health: A longitudinal study. Journal of Psychosomatic Research, 55(4), 317320.

Hobfoll, S. E., \& Freedy, J. (1993). Conservation of resources: A general theory applied to burnout. In W.B. Schaufeli, C. Maslach, \& T. Marek (Eds), Professional burnout: Recent developments in theory and research (pp. 115-135). New York: Taylor \& Francis.

Hobfoll, S. E., \& Shirom, A. (2000). Conservation of resources theory: Applications to stress and management in the workplace. In R.T. Golembiewski (Ed.), Handbook of organization behaviour (2nd revised ed., pp. 57-81). New York: Dekker.

Hoge, C.W., Castro, C.A., Messer, S.C., McGurk, D., Cotting, D.I., \& Koffman, R.L. (2004). Combat duty in Iraq and Afghanistan, mental health problems, and barriers to care. The New England Journal of Medicine, 351(1), 13-22.

Hu, L., \& Bentler, P. M. (1999). Cutoff criteria for fit indexes in covariance structure analysis: Conventional criteria versus new alternatives. Structural Equation Modeling, 6(4), 1-55.
Idler, E.N., \& Benyamini, Y. (1997). Self-rated health and mortality: A review of twenty-seven community studies. Journal of Health and Social Behavior, 38, 21-37.

Jamshidian, M., \& Bentler, P.M. (1999). ML estimation of mean and covariance structures with missing data using complete data routines. Journal of Educational and Behavioral Statistics, 24(1), 21-41.

Kanner, A.D., Coyne, J.C., Schaefer, C., \& Lazarus, R.S. (1981). Comparison of two modes of stress measurements: Daily hassles and uplifts versus major life events. Journal of Behavioral Medicine, 4, 1-39.

Lee, S., \& Hershberger, S. (1990). A simple rule for generating equivalent models in covariance structure modeling. Multivariate Behavioral Research, 25, 313-334.

Maslach, C. (1982). Burnout: The cost of caring. Englewood Cliffs, NJ: Prentice Hall.

Maslach, C., \& Jackson, S.E. (1981). The measurement of experienced burnout. Journal of Occupational Behavior, 2(2), 99-113.

Melamed, S., Shirom, A., Toker, S., Berliner, S., \& Shapira, I. (2006). Burnout and risk of cardiovascular disease: Evidence, possible causal paths, and promising research directions. Psychological Bulletin, 132(3), 327-353.

Schaufeli, W.B. (2003). Past performance and future perspectives of burnout research. South African Journal of Industrial and Organisational Psychology, 29(4), 1-15.

Schaufeli, W.B., \& Enzmann, D. (1998). The burnout companion to study and practice: A critical analysis. Washington, DC: Taylor \& Francis.

Schaufeli, W. B., \& Buunk, B.P. (2003). Burnout: An overview of 25 years of research and theorizing. In M.J. Schabracq, J.A.M. Winnubst, \& C.L. Cooper (Eds), The handbook of work and health psychology (2nd ed., pp. 383-429). West Sussex, UK: Wiley.

Shirom, A. (1989). Burnout in work organizations. In C.L. Cooper, \& I. Robertson (Eds), International review of industrial and organizational psychology (pp. 26-48). New York: Wiley.

Shirom, A. (2009). Job-related burnout: A review of major research foci and challenges. In J.C. Quick, \& L.E. Tetric (Eds), Handbook of occupational health psychology (2nd ed.). Washington DC: American Psychological Association.

Shirom, A., \& Melamed, S. (2006). A comparison of the construct validity of two burnout measures in two groups of professionals. International Journal of Stress Management, 13(2), 176-200.

Stewart, A.L., \& Ware, J.E. (1992). Measuring functioning and well-being: The medical outcome study approach (pp. 345-371). Durham, NC: Duke University Press.

Taris, T.W. (2006). Is there a relationship between burnout and objective performance? A critical review of 16 studies. Work \& Stress, 20(4), 316-334.

Westman, M., Hobfoll, S.E., Chen, S., Davidson, O.B., \& Laski, S. (2005). Organizational stress through the lens of Conservation of Resources (COR) theory. In P. Perrewe, \& D.C. Ganster (Eds), Research in occupational stress and well being, Vol. 4. (pp. 167-220). Oxford, England: JAI Press/Elsevier.

Yuan, K.H., \& Bentler, P.M. (2000). Three likelihood-based methods for mean and covariance structure analysis with nonnormal missing data. Sociological Methodology, 30, 165-200. 